\title{
Technological Advancements in Rehabilitation Sciences; Practice and Challenges from a Pakistani Perspective
}

\section{Syed Shakil Ur Rehman}

Professor, Faculty of Rehabilitation and Allied Health Sciences, Riphah International University Lahore Campus

\section{Address of Correspondence: \\ Syed Shakil Ur Rehman \\ Email: shakil.urrehman@riphah.edu.pk \\ ORIC Id: $\underline{0000-0002-6682-9896}$}

The world is facing remarkable change in science and technology from the end decades of the last century to the first two decades of the current century. Rehabilitation sciences professions have also faced the same technological change as other professions of medical and allied health sciences, where manual assistive devices, diagnostic tools, treatment techniques, and modalities were replaced by digital and computer-based modern technology. Technological advancements give more mobility to persons with brain and spinal cord injuries, provide more accuracy in the diagnosis of musculoskeletal disorders, and enhance treatments outcomes through improvements in signs, symptoms, and quality of life.

Robotic devices like orthosis and exoskeletons are used for improving locomotion in the geriatric population and to restore mobility in the lower limbs affected by brain and spinal cord-related injuries. Robotic devices include treadmill, foot plate-based, and overground gait trainers, while stationary and active foot orthosis for ankle rehabilitation. ${ }^{1}$ Robotic technology is supporting the population challenges, shortage of skilled rehabilitation professionals and inculcating the advancements of technology into the rehabilitation of patients with special abilities. ${ }^{2}$ Literature supported the positive effects of robotic rehabilitation on mobility, function, and quality of life in patients with spinal cord injury while improving motor function, activities, and participation in patients with stroke. ${ }^{3-4}$

Virtual reality (VR) based rehabilitation is used by physical therapists, occupational therapists, and speechlanguage pathologists for the rehabilitation of patients with musculoskeletal, neurological, and cardiorespiratory dysfunctions. These VR devices are ranged from nonimmersive, semi-immersive, fully immersive to augmentative and collaborative used for an individual-based rehabilitation as well as group-based rehabilitation. VR-based rehabilitation
Cite This Article as: Technological Advancements in Rehabilitation Sciences; Practice and Challenges from a Pakistani Perspective JRCRS. 2021; 9(1): 41-42. DOI: 10.53389/JRCRS.2021090200

improves cognition and motor recovery by increasing motivation and participation in stroke patients. ${ }^{5-6}$

Therapeutic use of ultrasound (US) is well established in the literature for the management of musculoskeletal conditions but now musculoskeletal ultrasound (MSU) is gaining evidence for the diagnosis of musculoskeletal pathologies. MSU imaging-guided physical therapy interventions can reduce inflammation and effusion by absorbing lesion tissue in the hemiplegic shoulder. ${ }^{7} \mathrm{MSU}$ imaging could be part of clinical decision-making in the management of cervicogenic headache for restoration of position, mobility, spasm, and posture. ${ }^{8}$

Spinal decompression tables are used in the management of spinal conditions. Non-surgical spinal decompression and conventional spinal traction are equally effective in pain management, enhance the functional status and depressive moods improvements in patients with disc herniation. ${ }^{9}$ Non-surgical spinal decompression table along with routine treatment has positive effects on pain, paresthesia, and numbness in patients with chronic low back pain. ${ }^{10}$ Nonsurgical spinal decompression tables are an effective modality for the management of pain, paresthesia, and weakness in neck and back pain. ${ }^{11}$

Globally the developed and economically better nations have coped well by inculcating modern technology and advancements into rehabilitation practice and succeeded in transferring its benefits to the end-users. Pakistan is a third world developing country lacking the latest technology in rehabilitation practice due to a lack of updated curriculum, training of professionals, and availability of budget. To train new professionals on the latest technology, it is essential for rehabilitation degree programs to update their curricula that should be in line with global advancements in technology. To enable already graduated professionals to work with modern technology, more continuous professional development 
programs must be designed, and more budget must be allocated for rehabilitation especially in the domain of technological advancements.

\section{References}

1. Piotrowicz E, Piotrowicz RJEjopc. Cardiac telerehabilitation: current situation and future challenges. Eur. J. Prev. Cardiol. 2013;20(2_suppl):12-6.

2. Pavy B, lliou MC, Meurin P, Tabet J-Y, Corone SJAoim. Safety of exercise training for cardiac patients: results of the French registry of complications during cardiac rehabilitation. Arch. Intern. Med 2006;166(21):2329-34.

3. Scherrenberg $M$, Wilhelm $M$, Hansen $D$, Völler $H$, Cornelissen V, Frederix I, et al. The future is now: a call for action for cardiac telerehabilitation in the COVID-19 pandemic from the secondary prevention and rehabilitation section of the Eur. J. Prev. Cardiol. 2021;28(5):524-40.

4. Nuara A, Fabbri-Destro M, Scalona E, Lenzi SE, Rizzolatti G, Avanzini PJJon. Telerehabilitation in response to constrained physical distance: An opportunity to rethink neurorehabilitative routines. J. Neurol. 2021:1-12.

5. Ahmad I, Iqbal S, Shahzad Jamil MKJLA. A Systematic Literature Review of E-Banking Frauds: Current Scenario and Security Techniques. Linguistica Antverpiensia 2021:3509-17--17.

6. Pramuka M, van Roosmalen LJljot. Telerehabilitation technologies: Accessibility and usability. Int J Telerehabilitation. 2009;1(1):85.

\section{Copyright Policy}

All Articles are made available under a Creative Commons "Attribution-NonCommercial $\mathbf{4 . 0}$ International" license. (https://creativecommons.org/licenses/by-nc/4.0/). Copyrights on any open access article published by Journal Riphah college of Rehabilitation Science (JRCRS) are retained by the author(s). Authors retain the rights of free downloading/unlimited e-print of full text and sharing/disseminating the article without any restriction, by any means; provided the article is correctly cited. JRCRS does not allow commercial use of the articles published. All articles published represent the view of the authors and do not reflect the official policy of JRCRS. 